\title{
Knowledge, Attitudes and Perceptions Among Non-Blood Donor Female Health Care Professionals
}

\author{
Muhammad Bilal $^{1}$, Abdul Haseeb ${ }^{1}$, Ibrahim Zahid ${ }^{1}$, Sehan Siraj Lashkerwala ${ }^{1}$, Fawad Saeeduddin², Muhammad \\ Saad $^{3}$, Mohammad Hussham Arshad ${ }^{4}$, Manpreet Moorpani ${ }^{5}$, Midhat Zafar Khan ${ }^{5}$, Ahsan Tariq ${ }^{5}$, Haya Habib ${ }^{5}$, \\ Tehrema Islam ${ }^{6} \&$ Rohan Advani ${ }^{5}$ \\ ${ }^{1}$ Dow University of Health Sciences, Karachi, Pakistan \\ ${ }^{2}$ Jinnah Sindh Medical University, Karachi, Pakistan \\ ${ }^{3}$ Department of Pulmonology, Jinnah Postgraduate Medical Center, Karachi, Pakistan \\ ${ }^{4}$ Aga Khan University Hospital, Karachi, Pakistan \\ ${ }^{5}$ The Lyceum, Karachi, Pakistan \\ ${ }^{6}$ Karachi Grammar School, Karachi, Pakistan \\ Correspondence: Muhammad Bilal, Dow University of Health Sciences, Karachi, Pakistan, A/215, Block: 5, \\ Gulshan-e-Iqbal, Karachi, Pakistan. Tel: 92-324-222-0872. E-mail: bilalmemon_744@hotmail.com
}

Received: June 22, 2015 Accepted: July 22, 2015 Online Published: August 18, 2015

doi:10.5539/gjhs.v8n4p203

URL: http://dx.doi.org/10.5539/gjhs.v8n4p203

\begin{abstract}
Introduction: Blood donation is necessary in order to maintain an adequate supply of blood to patients who are suffering from any kind of disease or trauma, which requires them to have blood transfusion. Female non-blood donors are generally low in number. Therefore, this research was carried out to assess the main reasons behind the lack of blood donations made by females, and their knowledge, attitude and perceptions towards voluntary blood donation.
\end{abstract}

Methodology: A cross-sectional study was conducted on 664 female health professionals, who were selected by non-probability convenience sampling from two tertiary care hospitals. A pretested questionnaire was presented to the sample population, and the data was entered and analyzed on SPSS (V17).

Results: $94.6 \%$ were aware with the fact that blood is screened for AIDS, Hepatitis B and C before transfusion. Moreover, $83.7 \%$ said that they will only donate blood if a family, relative or friend would need it and similarly 83.4\% suggested that they would donate blood if blood donation camps are arranged in hospital premises. $81.8 \%$ thought that blood donors can contract Hepatitis B after donation whereas only 29.5\% did not blood due already blood loss in menstrual cycle.

Conclusion: The participants had adequate knowledge about the benefits of blood donation. The most important reason identified for not donating blood is the lack of facilities within the workplace or lack of approach by responsible authorities. The results of the study may help in minimizing the misconceptions of the participants about blood transfusion, which would increase their contribution towards blood donation.

Keywords: non-blood donors, female health care professionals, knowledge, perceptions, tertiary care hospitals

\section{Introduction}

Blood donation refers to the process of collecting, testing, preparing and storing blood and its components (http://www.mayoclinic.org/). The purpose of the blood collection and distribution system is to help ensure an adequate supply of blood for accident victims, people needing surgery, people suffering from liver disease and those suffering from certain diseases like anemia, thalassemia, hemophilia, as well as for medical research (http://www.mayoclinic.org/). For a country to maintain a basic, self-sufficient supply, it is roughly estimated that $2-2.5 \%$ of the population must give blood regularly [World Health Organization, Blood safety: Key global fact and figures in 2011. (Online) (Cited 2013 July 1). Available from URL: http://www.who.int/topics/blood_safety/en/]. According to WHO, about 10000 blood centers in 168 countries report collecting a total of 83 million donations. Women constitute to only $30 \%$ of global blood donations and in 20 of the 111 reporting countries, less than 10\% donations are given by female donors (Bani \& Giussani, 2010). 
Men have given blood more often than women. Consequently, the blood transfusion services are facing a major challenge to meet the increasing demand of the blood.

In Pakistan more than 1.5 million pints of blood are collected each year. Among them about $65 \%$ is from replacement donors, $25 \%$ from volunteer donors and only about $10 \%$ from professional donors (Asif, Kokhar, \& Ilahi, 2004). Unfortunately, Pakistan is one of those countries where blood donation rate is less than $1 \%$, as stated in a newspaper published in 2012.According to estimates, over $70 \%$ blood donations in Pakistan are replacement or paid for donations while unscreened blood transfusion is done in over $50 \%$ of the cases. Reports by WHO suggest that over $90 \%$ of total blood transfused in Pakistan is donated by the friends and relatives of patients. However, despite efforts to control the practice, around $10 \%-20 \%$ of the blood supply is still donated by professional donors. The average number of blood donations per 1,000 populations is 12 times higher in high income countries than in low-income countries [World Health Organization (WHO) Blood donation factsheet 2009].The factors responsible for such low blood collection in Pakistan include lack of education and awareness about the need of safe blood in the community, importance of voluntary unpaid blood transfusion (VUBD) and high prevalence of hepatitis B, C, HIV/AIDS and anemia.

Many reports in the past have highlighted the insufficient knowledge and numerous misconceptions of people about blood donation (Kowsalya, Vijakumar, \& Chidambaram, 2013). Keeping in view the significance of blood donation and the decreasing fraction of transfused blood over recent years, this research was conducted to evaluate the reasons as to why sufficient blood donations are not made. Since female donors are much less than male donors, the research focused on females and their attitude towards not donating blood. Therefore, the main objective of the study was to assess the knowledge, attitudes and perceptions among non-blood donor female health professionals of tertiary care hospitals in Karachi towards voluntary blood donation.

\section{Methodology}

A descriptive, cross sectional survey was conducted in two tertiary care hospitals of Karachi over a period of 2 weeks in March 2015. Assuming the knowledge of blood donation among non-blood donor female health care professionals to be $50 \%$ (taking $99 \%$ level of significance and $1 \%$ confidence limit), the sample size calculated was 664. Researchers, after explaining the purpose of study and taking written consent, presented a self-administered questionnaire to the sample population using the non-probability convenience sampling method. Health care professionals who did not consent to participate were excluded from the study. The study was performed after the approval from the Institutional Review Board of the Dow University of Health Sciences.

This multicenter study was conducted at Civil hospital and Jinnah post graduate medical center, Karachi. Questionnaires were distributed among the target population after a pilot study which included female nurses, interns, residents and consultants who had never donated blood in their life. Exclusion criteria included all male health care professionals, female health care professionals who had donated blood at least once in their lifetime, females suffering from hemophilia and thalassemia; and females on blood thinners. The questionnaire was divided into 3 major parts. The first part consists of the demographic characteristics (for e.g. age, sex, income) of the female health care professional. Second part was related to the knowledge of target population regarding blood donation. Question investigating perceptions of not donating blood concluded the third part of the questionnaire.

Data was collected and entered on SPSS (V17) software. The same software was used for data management and analysis. Standard deviation and mean were calculated for the continuous variables like age. Frequencies and percentages were calculated for qualitative variables like gender, level of education, marital status etc. Chi-square was used to deduce the association between the knowledge and perceptions of blood donation of different medical health professionals. P value less than 0.05 was taken as significant.

\section{Results}

A total of $\mathrm{N}=664$ participants fulfilling the inclusion criteria were recruited in the survey. Out of them $39.76 \%$ $(\mathrm{N}=264)$ were Interns, 23.34\% $(\mathrm{N}=155)$ were residents, 4.37\% $(\mathrm{N}=29)$ were consultants and 32.53\% $(\mathrm{N}=216)$ were nurses. The mean age of participants was $26.7 \pm 2.5$. Seventy one percent $(\mathrm{N}=469)$ had level of education of bachelors, 59.64\% ( $\mathrm{N}=396)$ participants had income of 10,000-25,000 rupees, $69.28 \%(\mathrm{~N}=460)$ of study population was unmarried and consequently $78.31 \%$ of the participants $(\mathrm{N}=520)$ were childless. Table 1 depicts demographics of female health professionals

When non blood donor female participants were questioned about their knowledge and attitude towards blood donation, 94.6\% $(\mathrm{N}=628)$ knew that blood is screened for AIDS, Hepatitis B and C before transfusion and similar frequency was noted for those who responded that blood can be used in cancer treatment. Eight four 
percent of the participants $(\mathrm{N}=555)$ were aware about the fact that all surgical procedures require blood transfusion and transfused blood can be stored, 91.3\% ( $\mathrm{N}=606)$ said that blood is required in accident and emergency department and $81.8 \%(\mathrm{~N}=543)$ were also aware that blood can be donated during fast. Moreover, $83.7 \%(\mathrm{~N}=556)$ said that they will only donate blood if a family, relative or friend would need it and similarly 83.4\% ( $\mathrm{N}=554)$ suggested that they would donate blood if blood donation camps are arranged in hospital premises. The most prevalent misconception among the respondents was that the blood donor has risk for contracting infections as $81.8 \%(\mathrm{~N}=543)$ said for Hepatitis $\mathrm{B}, 83.4 \%(\mathrm{~N}=554)$ said for Hepatitis $\mathrm{C}$ and $78.7 \%$ $(\mathrm{N}=523)$ considered HIV to be contracted after donating blood. However, the misconceptions regarding the risk factors associated with blood transfusion were significantly low as only $16.1 \%(\mathrm{~N}=107)$ considered weight gain after blood donation, 20.0\% ( $\mathrm{N}=133)$ said weight loss, 5.4\% ( $\mathrm{N}=36)$ said infertility and only $20 \%(\mathrm{~N}=133)$ thought of having severe fatigue and bruising at injection site. Additionally, when questioned about the conditions in which blood should not be donated, 59.0\% ( $\mathrm{N}=392)$ said alcoholics, 69.4\% ( $\mathrm{N}=461)$ responded communicable disease, $75.9 \%(\mathrm{~N}=504)$ considered that having history of Malaria/Hepatitis and $40.6 \%(\mathrm{~N}=270)$ thought that person having history of allergies should not donate blood. Lastly, only $58.1 \%(\mathrm{~N}=386)$ replied positively with regards to donating blood in future. Table 2 depicts knowledge and attitude of female health professionals.

When enquired about the perceptions and reasons for not donating blood, 29.5\% ( $\mathrm{N}=196)$ did not blood due to blood loss through menstrual cycle, 36.7\% ( $\mathrm{N}=250)$ had no time for going to blood bank, $13 \%(\mathrm{~N}=86)$ considered female blood as impure and it may harm the recipient, 34.5\% ( $\mathrm{N}=229)$ did not trust the blood banks, $31.5 \%(\mathrm{~N}=209)$ had fear of needle prick and $29.5(\mathrm{~N}=196)$ had apprehension of syncope and becoming weak after donation. Furthermore, 31.3\% ( $\mathrm{N}=208)$ did not consider them strong enough to give blood as men, $47 \%$ $(\mathrm{N}=312)$ said that they were never asked to donate, $20.1 \%(\mathrm{~N}=133)$ did not considered their information to be sufficient regarding donation. However, $15.4 \%(\mathrm{~N}=102)$ had fear of too much blood to be withdrawn, 32.0\% $(\mathrm{N}=212)$ considered them to be not eligible medically and only $17.6 \%(\mathrm{~N}=117)$ considered process to be long and boring. Table 3 depicts perceptions and reasons associated among non-blood donor female health professionals.

Table 1. Demographics of female health professionals

\begin{tabular}{lll}
\hline Demographic Characteristics & $\mathrm{n}$ & $\%$ \\
\hline 1. Designation & 264 & 39.76 \\
Intern & 155 & 23.34 \\
Resident & 29 & 4.367 \\
Consultant & 216 & 32.53 \\
Nurse & $26.7 \pm 2.5$ & - \\
2. Age (Mean \pm SD) & & \\
3. Level Of Education & 56 & 8.434 \\
Matric & 82 & 12.35 \\
Intermediate & 469 & 70.63 \\
Bachelors & 57 & 8.584 \\
Masters & & \\
4. Income (Rupees) & 396 & 59.64 \\
10,000-25,000 & 187 & 28.16 \\
26,000-50,000 & 81 & 12.20 \\
> 51,000 & & \\
5. Marital status & 204 & 30.72 \\
Married & 460 & 69.28 \\
Unmarried & & \\
6. Number of children & & \\
\hline
\end{tabular}




\begin{tabular}{lll}
\hline 0 & 520 & 78.31 \\
$1-2$ & 103 & 15.51 \\
$3-4$ & 41 & 6.175 \\
\hline
\end{tabular}

Table 2. Knowledge and attitude of female health professionals

\begin{tabular}{|c|c|c|c|c|c|c|c|c|c|}
\hline & \multicolumn{2}{|c|}{$\begin{array}{l}\text { Intern } \\
(\mathrm{n}=264)\end{array}$} & \multicolumn{2}{|c|}{$\begin{array}{l}\text { Resident } \\
(\mathrm{n}=155 \text { ) }\end{array}$} & \multicolumn{2}{|c|}{$\begin{array}{l}\text { Consultant } \\
(\mathrm{n}=29)\end{array}$} & \multicolumn{2}{|c|}{$\begin{array}{l}\text { Nurse } \\
(\mathrm{n}=216)\end{array}$} & \multirow[t]{2}{*}{ p-values } \\
\hline & $\mathrm{n}$ & $\%$ & $\mathrm{n}$ & $\%$ & $\mathrm{n}$ & $\%$ & $\mathrm{n}$ & $\%$ & \\
\hline \multicolumn{9}{|c|}{ Blood is screened for aids, hepatitis b \& c before transfusion } & $<0.001$ \\
\hline Yes & 260 & $41.4 \%$ & 155 & $24.7 \%$ & 29 & $4.6 \%$ & 184 & $29.3 \%$ & \\
\hline No & 4 & $11.1 \%$ & 0 & $.0 \%$ & 0 & $.0 \%$ & 32 & $88.9 \%$ & \\
\hline \multicolumn{9}{|c|}{ All surgical procedures require blood transfusion } & $<0.001$ \\
\hline Yes & 240 & $43.2 \%$ & 135 & $24.3 \%$ & 28 & $5.0 \%$ & 152 & $27.4 \%$ & \\
\hline No & 24 & $22.0 \%$ & 20 & $18.3 \%$ & 1 & $.9 \%$ & 64 & $58.7 \%$ & \\
\hline \multicolumn{9}{|c|}{ Blood can be used in cancer treatment } & 0.305 \\
\hline Yes & 260 & $41.4 \%$ & 155 & $24.7 \%$ & 29 & $4.6 \%$ & 184 & $29.3 \%$ & \\
\hline No & 4 & $11.1 \%$ & 0 & $.0 \%$ & 0 & $.0 \%$ & 32 & $88.9 \%$ & \\
\hline \multicolumn{9}{|c|}{ Blood is required in emergencies } & $<0.001$ \\
\hline Yes & 244 & $40.3 \%$ & 144 & $23.8 \%$ & 28 & $4.6 \%$ & 190 & $31.4 \%$ & \\
\hline No & 20 & $34.5 \%$ & 11 & $19.0 \%$ & 1 & $1.7 \%$ & 26 & $44.8 \%$ & \\
\hline \multicolumn{9}{|l|}{ Blood can be stored } & $<0.001$ \\
\hline Yes & 240 & $43.2 \%$ & 135 & $24.3 \%$ & 28 & $5.0 \%$ & 152 & $27.4 \%$ & \\
\hline No & 24 & $22.0 \%$ & 20 & $18.3 \%$ & 1 & $.9 \%$ & 64 & $58.7 \%$ & \\
\hline \multicolumn{9}{|c|}{ Blood can be donated while keeping a fast } & $<0.001$ \\
\hline Yes & 226 & $41.6 \%$ & 140 & $25.8 \%$ & 25 & $4.6 \%$ & 152 & $28.0 \%$ & \\
\hline No & 38 & $31.4 \%$ & 15 & $12.4 \%$ & 4 & $3.3 \%$ & 64 & $52.9 \%$ & \\
\hline \multicolumn{9}{|c|}{ I will donate blood if a family, relative, or friend needs } & $<0.001$ \\
\hline Yes & 230 & $41.4 \%$ & 133 & $23.9 \%$ & 21 & $3.8 \%$ & 172 & $30.9 \%$ & \\
\hline No & 34 & $31.5 \%$ & 22 & $20.4 \%$ & 8 & $7.4 \%$ & 44 & $40.7 \%$ & \\
\hline \multicolumn{9}{|c|}{ I would donate blood if blood donation camp arrange in the hospital premises } & $<0.001$ \\
\hline Yes & 232 & $41.9 \%$ & 145 & $26.2 \%$ & 21 & $3.8 \%$ & 156 & $28.2 \%$ & \\
\hline No & 32 & $29.1 \%$ & 10 & $9.1 \%$ & 8 & $7.3 \%$ & 60 & $54.5 \%$ & \\
\hline \multicolumn{10}{|c|}{ Which infectious diseases do you think can be contracted after blood donation? } \\
\hline a. Hepatitis B & & & & & & & & & $<0.001$ \\
\hline Yes & 226 & $41.6 \%$ & 140 & $25.8 \%$ & 25 & $4.6 \%$ & 152 & $28.0 \%$ & \\
\hline No & 38 & $31.4 \%$ & 15 & $12.4 \%$ & 4 & $3.3 \%$ & 64 & $52.9 \%$ & \\
\hline b. Hepatitis C & & & & & & & & & $<0.001$ \\
\hline Yes & 232 & $41.9 \%$ & 145 & $26.2 \%$ & 21 & $3.8 \%$ & 156 & $28.2 \%$ & \\
\hline No & 32 & $29.1 \%$ & 10 & $9.1 \%$ & 8 & $7.3 \%$ & 60 & $54.5 \%$ & \\
\hline c. Malaria & & & & & & & & & $<0.001$ \\
\hline Yes & 90 & $41.5 \%$ & 77 & $35.5 \%$ & 12 & $5.5 \%$ & 38 & $17.5 \%$ & \\
\hline No & 174 & $38.9 \%$ & 78 & $17.4 \%$ & 17 & $3.8 \%$ & 178 & $39.8 \%$ & \\
\hline
\end{tabular}




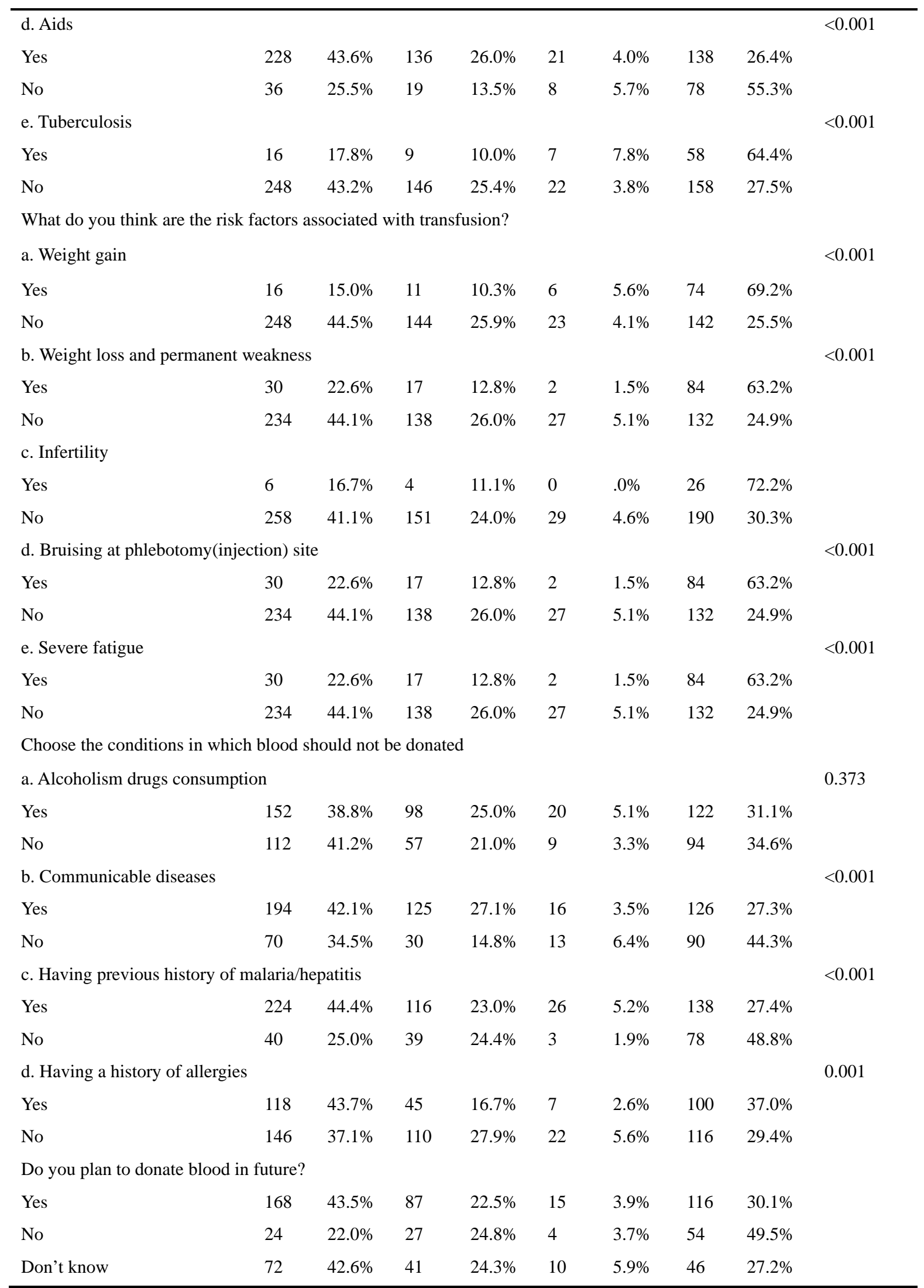


Table 3. Perceptions and reasons associated among non-blood donor female health professionals

\begin{tabular}{llllll}
\hline $\begin{array}{l}\text { Intern } \\
(\mathrm{n}=264)\end{array}$ & $\begin{array}{l}\text { Resident } \\
(\mathrm{n}=155)\end{array}$ & $\begin{array}{l}\text { Consultant } \\
(\mathrm{n}=29)\end{array}$ & $\begin{array}{l}\text { Nurse } \\
(\mathrm{n}=216)\end{array}$ & P-Values \\
\cline { 2 - 6 } & $\mathrm{n}$ & $\mathrm{n}$ & $\mathrm{n}$ & $\mathrm{n} \%$ & $\mathrm{n}$ \\
\hline
\end{tabular}

1. You do not prefer donating blood due to already losing blood through menstruation (concern of $<0.001$ having low blood)

$\begin{array}{lllllllll}\text { Yes } & 38 & 19.4 \% & 27 & 13.8 \% & 3 & 1.5 \% & 128 & 65.3 \% \\ \text { No } & 226 & 48.3 \% & 128 & 27.4 \% & 26 & 5.6 \% & 88 & 18.8 \%\end{array}$

2. No time for going to a blood bank (too busy caring for the family)

0.001

$\begin{array}{lllllllll}\text { Yes } & 74 & 30.3 \% & 60 & 24.6 \% & 12 & 4.9 \% & 98 & 40.2 \% \\ \text { No } & 190 & 45.2 \% & 95 & 22.6 \% & 17 & 4.0 \% & 118 & 28.1 \%\end{array}$

3. Dirtiness of menstrual blood (Napak/impurity of female blood)

NA

$\begin{array}{lllllllll}\text { Yes } & 10 & 11.6 \% & 8 & 9.3 \% & 0 & .0 \% & 68 & 79.1 \% \\ \text { No } & 254 & 43.9 \% & 147 & 25.4 \% & 29 & 5.0 \% & 148 & 25.6 \%\end{array}$

4. The blood may harm the recipient

$\begin{array}{lllllllll}\text { Yes } & 16 & 18.6 \% & 10 & 11.6 \% & 2 & 2.3 \% & 58 & 67.4 \% \\ \text { No } & 248 & 42.9 \% & 145 & 25.1 \% & 27 & 4.7 \% & 158 & 27.3 \%\end{array}$

5. You don't trust the blood banks distribution facility and sterilization of equipment

$\begin{array}{lllllllll}\text { Yes } & 66 & 28.8 \% & 57 & 24.9 \% & 6 & 2.6 \% & 100 & 43.7 \% \\ \text { No } & 198 & 45.5 \% & 98 & 22.5 \% & 23 & 5.3 \% & 116 & 26.7 \%\end{array}$

6. A fear of needle prick

$\begin{array}{lllllllll}\text { Yes } & 60 & 28.7 \% & 40 & 19.1 \% & 11 & 5.3 \% & 98 & 46.9 \% \\ \text { No } & 204 & 44.8 \% & 115 & 25.3 \% & 18 & 4.0 \% & 118 & 25.9 \%\end{array}$

7. Apprehension of syncope and becoming weak after donation

$\begin{array}{lllllllll}\text { Yes } & 60 & 30.6 \% & 35 & 17.9 \% & 7 & 3.6 \% & 94 & 48.0 \% \\ \text { No } & 204 & 43.6 \% & 120 & 25.6 \% & 22 & 4.7 \% & 122 & 26.1 \%\end{array}$

8. You do not feel strong enough to give blood as men

$\begin{array}{lllllllll}\text { Yes } & 62 & 29.8 \% & 31 & 14.9 \% & 9 & 4.3 \% & 106 & 51.0 \% \\ \text { No } & 202 & 44.3 \% & 124 & 27.2 \% & 20 & 4.4 \% & 110 & 24.1 \%\end{array}$

9. No-one ever asked for donation and never thought to donate

$\begin{array}{lllllllll}\text { Yes } & 100 & 32.1 \% & 63 & 20.2 \% & 15 & 4.8 \% & 134 & 42.9 \% \\ \text { No } & 164 & 46.6 \% & 92 & 26.1 \% & 14 & 4.0 \% & 82 & 23.3 \%\end{array}$

10. Don't have enough information

$\begin{array}{lllllllll}\text { Yes } & 22 & 16.4 \% & 15 & 11.2 \% & 1 & .7 \% & 96 & 71.6 \% \\ \text { No } & 242 & 45.7 \% & 140 & 26.4 \% & 28 & 5.3 \% & 120 & 22.6 \%\end{array}$

11. Fear that they would take too much blood

$\begin{array}{lllllllll}\text { Yes } & 18 & 17.6 \% & 8 & 7.8 \% & 2 & 2.0 \% & 74 & 72.5 \% \\ \text { No } & 246 & 43.8 \% & 147 & 26.2 \% & 27 & 4.8 \% & 142 & 25.3 \%\end{array}$

12. Not eligible medically

$\begin{array}{lllllllll}\text { Yes } & 70 & 32.9 \% & 49 & 23.0 \% & 2 & .9 \% & 92 & 43.2 \% \\ \text { No } & 194 & 43.0 \% & 106 & 23.5 \% & 27 & 6.0 \% & 124 & 27.5 \%\end{array}$

13. Process is long and boring

NA

$<0.001$

$<0.001$ 


\begin{tabular}{lllllllll}
\hline Yes & 22 & $18.8 \%$ & 29 & $24.8 \%$ & 0 & $.0 \%$ & 66 & $56.4 \%$ \\
No & 242 & $44.2 \%$ & 126 & $23.0 \%$ & 29 & $5.3 \%$ & 150 & $27.4 \%$ \\
\hline
\end{tabular}

NA; Not applicable due to cells have expected count less than 5.

\section{Discussion}

This descriptive study was conducted to investigate the current information regarding knowledge, attitude and perceptions among non-blood donor female health professionals in leading teaching hospitals of Karachi. The results will be helpful in execution of relevant donor gathering strategies, because this subset of population can contribute significantly to augment health promoting activities in society. This task can be achieved by hospitals blood bank by increasing appropriate distribution of collected blood (Vos, 1998) and also by increasing healthy blood donor recruitment (Gillespie \& Hillyer, 2002). The factors leading to decrease blood donation has become an important concern and are studied nowadays worldwide to increase voluntary blood collection (Allen \& Butler, 1993).

The demographic features of previous data indicated female donors to be very few in number as compare to male donors as shown by Gillespie (Gillespie \& Hillyer, 2002). Moreover, a work by Hollingsworth reported only 1\% female donors among donor population (Hollingsworth \& Wildman, 2004). Therefore the issue needs to be given due consideration, as female health professionals are the most accessible source of voluntary blood donation.

In general, the knowledge of participants towards benefits of blood donation is sufficient and are well aware with conditions in which blood should not be donated as the study participants belong to medical profession. This is in line with the finding of several university students at India (Giri \& Phalke, 2012), Bangladesh (Hosain, Anisuzzaman, \& Begum, 1997) and Thailand (Wiwanitkit, 2002). However, Safizadeh (Safizadeh, Pourdamghan, \& Mohamadi, 2007) in Iran found that the awareness regarding blood donation was inadequate while a similar study in Pakistan also reported that there is a lack of knowledge and awareness regarding benefits of blood donation (Saeed, Munir, \& Shahid, 2011). This is the point to ponder for blood transfusion services that despite sufficient knowledge among female health professionals, a significant number do not donate blood. They must be encouraged in order to increase voluntary blood collection.

Surprisingly, majority of the participants (83\%) do not donate blood due to lack of facilities and absence of blood donation camp in hospital premises. The results are congruent with the findings of another study conducted on the undergraduates of a medical college of Pakistan (Ahmed, Zafar, Khan, Anjum, \& Siddique, 2014), where majority of the participants reported the same reason. Therefore, steps should be taken to organize blood donor societies and camps within the premises of work place. Furthermore, it should be mandatory by health ministry that health professional should donate blood at least once or twice in a year. This will increase blood donor pool greatly.

The current study further highlighted that among the respondents, the most widespread misconception was that the blood donor has risk for contracting infection like HIV or Hepatitis B and C. This finding has been corroborated by findings of studies carried out in past. A similar study in Pakistan revealed that $10.2 \%$ of the participants do not donate blood because of the fear of contraction of diseases after blood donation (Hosain, Anisuzzaman, \& Begum, 1997). Furthermore, a study reported misjudgment of acquiring AIDS and hepatitis due to blood donation activities among the French population (Munoz, Bacq, \& Mullet, 2002). A study in Nigeria reported that $52.4 \%$ students have a similar misconception of acquiring AIDS and hepatitis by blood donation (Olaiya, Alkija, Ajala, \& Olatunji, 2004). Additionally, an Iranian study also reported that most of the students (66.6\%) had the same misbelief (Safizadeh, Pourdamghan, \& Mohamadi, 2007). We suggest that for the success of blood donation campaigns, it is necessary to remove these misconceptions and this could be achieved by the introduction of awareness programs through television, radio and newspaper which are a major source of information in Pakistan.

Additionally, our study also revealed that $47 \%$ of participants did not donate because they were not approached by anyone and never thought of donating. This is consistent with the another Saudi study where $45 \%$ did not donate for the same reason (Alam, \& MasalmehBel, 2004). Around 30\% of participants did not donate because of fear of needle prick, apprehension of syncope and becoming weak after donation. This is contradictory with work of Olaiya (Olaiya, Alkija, Ajala, \& Olatunji, 2004), where 60\% participants did not donate blood because of similar reasons.

The current study shows that the major motivation for donors was to help family or friends, for saving others' 
lives and altruism as responded by $85 \%$ of responders. This is in line with several studies which have indicated altruism as an important motivating factor among donors in Pakistan (Saeed, Munir, \& Shahid, 2011), India (Singh, Pandey, \&D'Souza, 2002) and Brazil (Thelma, Goncalez, \& Ester, 2008). However this is inconsistent with an American study where participants demanded for incentives like free blood investigations, lottery tickets and souvenirs over altruism (Glynn et al., 2003). Furthermore, very few people (13\%) reported female blood as impure and only $30 \%$ considered becoming anemic due to already losing blood in menstruation cycle. The frequency of perceptions like women do not feel strong as men, was also considerably low. This is incompatible with other studies conducted on Turkish (Dilsad, Tanriover, Hidiroglu, Gurbuz, \& Karavus, 2014) and Pakistani (Mumtaz, Bowen, \& Mumtaz, 2012) females which reported higher frequency of these perceptions, indicating reduced frequency of these perceptions among female health professionals.

Statistically significant differences were found with association of knowledge of blood donation and perceptions of not donating blood with medical health professionals. The inadequacy of knowledge along with perception frequency was higher in nurses and least in consultant doctors. The differences could be attributed to medical experience and higher medical knowledge. Therefore awareness programs must be made regular part in training of medical health professionals, so as to diffuse any misconceptions they have regarding voluntary blood donation.

To the best of our knowledge, this is the pioneer study in identifying the knowledge, attitudes and perceptions among non-blood donor female health professionals. The major limitation to our study is that since Karachi is a multicultural city with a broad diversity of traditions, data from two hospitals could not be generalized to other populations of country. Secondly, data on those who did not agree to participate in the survey was not collected and analyzed to exclude the possibility of a sampling bias.

\section{Conclusion}

In general, study participants had sound knowledge of benefits of blood donation and frequency of perceptions and reasons for not donating blood is low in comparison to other study populations. Alarmingly, few misconceptions are still prevalent among female health professionals. The most important reason identified for not donating blood is lack of facilities within the workplace or lack of approach by responsible authorities. So by performing this research, we tend to determine the misconceptions of females, especially the ones who form a part of the working population in the medical field. The results of the study may help to remove the concept of misunderstanding about current issues regarding blood donation and transfusion and may also facilitate to develop donor recruitment strategies within the healthcare premises and educational approaches to enhance blood donors' participation.

\section{Funding}

There was no funding for this research.

\section{Conflict of Interest}

The authors declare that there is no conflict of interests regarding the publication of this paper.

\section{References}

Ahmed, Z., Zafar, M., Khan, A. A., Anjum, U. M., \& Siddique, A. M. (2014). Knowledge, Attitude and Practices about Blood Donation among Undergraduate Medical Students in Karachi. Journal of Infectious Diseases and Therapy.

Alam, M., \& MasalmehBel, D. (2004). Knowledge, attitudes and practices regarding blood donation among the Saudi population. Saudi Med J, 25, 318-321. PMid: 15048169

Allen, J., \& Butler, D. D. (1993). Assessing the effects of donor knowledge and perceived risk on intentions to donate blood. J Health Care Mark, 13, 26-33. PMid: 10129813

Asif, N., Kokhar, N., \& Ilahi, F. (2004). Seroprevalence of HBV, HCV and HIV infection among voluntary non remunerated and replacement donors in Northern Pakistan. Pak J Med Sci, 20, 24-28.

Bani, M., \& Giussani, B. (2010). Gender differences in giving blood: a review of the literature. Blood Transfus, 8, 278-87. PMid: 20967170; PMCid: PMC2957494

Dilsad, S., Tanriover, O., Hidiroglu, S., Gurbuz, Y., \& Karavus, M. (2014). Knowledge, attitudes and beliefs of Turkish women towards blood donation. JPMA The Journal of the Pakistan Medical Association, 64(8), 869-73. PubMed PMID: 25252509.

Gillespie, T. W., \& Hillyer, C. D. (2002). Blood donors and factors impacting the blood donation decision. 
Transfus Med Rev, 16, 115-130. PMid: 11941574 http://dx.doi.org/10.1053/tmrv.2002.31461

Giri, P. A., \& Phalke, D. B. (2012). Knowledge and Attitude about Blood Donation Amongst Undergraduate Students of Pravara Institute of Medical Sciences Deemed University of Central India. Ann Trop Med Public Health, 5, 569-573. http://dx.doi.org/10.4103/1755-6783.109274

Glynn, S. A. et al. (2003). Attitudes toward blood donation incentives in the United States: implications for donor recruitment. Transfusion; 43, 7-16 http://dx.doi.org/10.1046/j.1537-2995.2003.00252.x PMid:12519425

Hollingsworth, B., \& Wildman, J. (2004). What population influences the decision to donate blood? Transfusion medicine; 14, 9-12. PMid: 15043587. http://dx.doi.org/10.1111/j.0958-7578.2004.00473.x

Hosain, G. M., Anisuzzaman, M., \& Begum, A. (1997). Knowledge and attitude towards voluntary blood donation among Dhaka University students in Bangladesh. East Afr Med J, 74, 549-553. PMid: 9487428 http://www.mayoclinic.org/

Kowsalya, V., Vijakumar, \& Chidambaram, R. (2013). A study on knowledge attitude and practice regarding blood donation among medical students in Poducherry, India. Pak J Biol Sci, 16(9), 439-442. PMid: 24498809 http://dx.doi.org/10.3923/pjbs.2013.439.442

Mumtaz, Z., Bowen, S., \& Mumtaz, R. (2012). Meanings of blood, bleeding and blood donations in Pakistan: implications for national vs global safe blood supply policies. Health Policy Plan, 27, 147-55. PMid: 21372061; PMCid: PMC3291874 http://dx.doi.org/10.1093/heapol/czr016

Munoz, M. T., Bacq, Y., \& Mullet, E. (2002). Misconceptions regarding hepatitis C in the French public. Prev Med, 34(6), 596-599. PMid: 12052019 http://dx.doi.org/10.1006/pmed.2002.1023

Olaiya, M. A., Alkija, W., Ajala, A., \& Olatunji, O. R. (2004). Knowledge, attitudes, beliefs and motivation towards blood donation among blod donors in Lagos, Nigeria. Transfusion Med, 14, 13-17. PMid: 15043588 http://dx.doi.org/10.1111/j.0958-7578.2004.00474.x

Saeed, N., Munir, E., \& Shahid, R. (2011). Beliefs about Blood Donation among Patients visiting OPDs of Pakistan's General Hospitals. JBUMDC, 1(2), 61-67.

Safizadeh, H., Pourdamghan, N., \& Mohamadi, B. (2007). University students awareness and attitude towards blood donation in Kerman city. IJBC, 3, 107-110.

Singh, B., Pandey, R. M., \& D'Souza, N. (2002). Knowledge, attitudes and socio-demographic factors differentiating blood donors from non-donors in an urban slum of Delhi. Indian J Commun Med, 27, 118-121.

Thelma, T., Goncalez, \& Ester, C. (2008). Knowledge, Attitudes and Motivations Among Blood Donors in São Paulo, Brazil. AIDS Behav, 12(4), S39-S47.

Vos, J. (1998). Guidelines for appropriate prescribing of blood transfusions in Tanzania. Postgraduate Doctor, 21, 77-80.

Wiwanitkit, V. (2002). Knowledge about blood donation among a sample of Thai university students. Vox Sang, 83, 97-99. http://dx.doi.org/10.1046/j.1423-0410.2002.00209.x

World Health Oraganization (WHO). Blood donation factsheet 2009.

World Health Organization. Blood safety: key global fact and figures in 2011. (Online) (Cited 2013 July 1). Retrieved from URL: http://www.who.int/topics/blood_safety/en/

\section{Copyrights}

Copyright for this article is retained by the author(s), with first publication rights granted to the journal.

This is an open-access article distributed under the terms and conditions of the Creative Commons Attribution license (http://creativecommons.org/licenses/by/3.0/). 